\title{
Conservação e Reabilitação Urbana
}

Os atos de conservar - como expressão da salvaguarda da história, memórias e valores culturais e urbanos - e do reabilitar - enquanto dispositivo de transformação e adequação às novas necessidades, usos, funções e exigências sociais e urbanas, manifestam, em modo crescente, a atualidade das atividades da construção e da intervenção em meio urbano. Os desafios colocados por ambos os atos sobre o património construído são representativos da atuação do LNEC (Laboratório Nacional de Engenharia Civil) que, desde longa data, realiza investigação, consultoria e um conjunto de iniciativas dirigidas à comunidade científica e técnica, nas quais se insere o ENCORE - Encontro de Conservação e Reabilitação de Edifícios. Os artigos reunidos neste dossiê resultam de uma seleção de trabalhos apresentados ao ENCORE 2020 - 4. ${ }^{\circ}$ Encontro de Conservação e Reabilitação de Edifícios - realizado em novembro de 2020, em Lisboa, com organização do LNEC.

Os artigos apresentados exploram a atualidade das questões da conservação e reabilitação de edifícios, nomeadamente a partir das suas componentes urbana e social. Cada vez mais, existe a consciência da influência destas ações nas cidades, seus edifícios, espaços públicos, patrimónios e ecossistemas, paralelamente intervindo na dinâmica social dos territórios urbanos. O paradigma do conservar e do reabilitar assume-se como uma problemática do conhecimento científico e técnico sobre a qual interessa refletir, discutir e complexificar. A par do fundamental interesse na definição de estratégias, planos, políticas e regulamentos, é importante apresentar e questionar experiências realizadas, avaliar e definir novos caminhos de reflexão, atuação e intervenção.

O artigo de Pier Paolo Pizzolato, que se intitula "Villa Sanhauá em João Pessoa - PB - Brasil: estudo de caso para a requalificação de centros históricos na América Latina”, discute a relação entre as lógicas de remodelação de áreas históricas com vista à sua valorização para o turismo, lazer, comércio e serviços numa área da região central da cidade de João Pessoa, no Nordeste do Brasil. A partir de visitas técnicas e da análise de projetos arquitetónicos de requalificação de determinados edifícios, o autor discute o papel da função habitar como fundamental no requalificar áreas desvitalizadas, contudo, observando os riscos que a gentrificação, promoção de um turismo de massas e privatização do espaço público para uso de bares e comércios, podem ter no incrementar da exclusão e segregação social e mesmo na expulsão dos moradores locais. Em conclusão, o autor aponta como fundamental proceder à avaliação destes processos, considerando o papel da realização de planos urbanísticos que evitem lógicas segregacionistas e especulativas, mas que igualmente assentem num planeamento mais amplo e orgânico.

No artigo "O Centro Histórico de Poços de Caldas/MG: O caso do quadrilátero do complexo hidrotermal e hoteleiro", Anamaria Canuto Sales de Oliveira e Ana Paula Farah percorrem o historial de atuação pública junto de um complexo hidrotermal e hoteleiro localizado na região Sudeste do Brasil - estado de Minas Gerais. As autoras discutem a relação entre a salvaguarda do património termal do centro histórico local e a sua significância cultural para a memória coletiva e respetiva apropriação social do território ao longo das intervenções públicas ali acionadas. No decurso da apresentação do historial de intervenções, as autoras observam a tendência para a promoção de uma imagem de marca e cultural do local que, todavia, nem sempre se coaduna com as práticas de preservação do património.

Francisco Javier González reflete sobre a evolução das políticas de reabilitação urbana em Madrid nos últimos anos com o artigo intitulado "Evolución de las políticas de rehabilitación y regeneración urbana en Madrid (19942018). De las áreas de rehabilitación preferente (ARP) al plan estratégico de regeneración urbana Madrid Recupera”. Ao abordar o historial de políticas de reabilitação e regeneração naquela realidade urbana, o autor observa o esgotamento de determinados modelos e a tendência mais recente para uma tentativa de adequação às novas necessidades urbanas, prosseguindo uma lógica que reflete um caráter mais integral de intervenção -

Copyright (C) 2021 (Menezes, M., Veiga, M.R.) 
habitações e/ou espaço público - e que se associa com as questões da sustentabilidade e da eficiência energética, da governância e da participação social, a colaboração interadministrativa, as novas dinâmicas de financiamento que vão do público ao privado e a criação de novos instrumentos de aplicação, de que a planificação estratégica da reabilitação urbana é representativa.

Joana Fazenda Mourão, por seu lado, identifica a importância de uma reabilitação integrada de edifícios habitacionais urbanos com valor cultural e a necessidade de instrumentos específicos de apoio técnico-científico para orientar as opções a tomar. Neste sentido, no artigo "Avaliação técnico-cultural e energético-ambiental da reabilitação de edifícios habitacionais urbanos", apresenta um método multicritério de diagnóstico que tem em conta o valor cultural e a avaliação de impactes técnico-cultural e energético-ambiental. $\mathrm{O}$ artigo desenvolve-se de forma a apresentar a estrutura e o modo de aplicação deste método, recorrendo para o efeito a uma aplicação-piloto e identificando hipóteses de desenvolvimentos futuros em função dos regulamentos portugueses em vigor.

Já Ana Cláudia Morais Fonseca dá-nos a conhecer uma experiência de intervenção municipal na cidade de Olinda - estado de Pernambuco (Brasil) - cuja salvaguarda do património edificado se realizou em consonância com o envolvimento da sociedade local. No artigo "Projeto Pinte seu Patrimônio: uma prática de preservação e cidadania", a autora relata uma iniciativa de reabilitação de edifícios históricos através da pintura de suas fachadas com cal colorida com diversos pigmentos. A referida experiência envolveu os moradores - que forneceram os materiais necessários para a realização da pintura -, os técnicos municipais - que coordenaram o projeto de intervenção - e pessoas condenadas - que atuaram como mão-de-obra na execução dos serviços de pintura. A autora sublinha o quão esta experiência, entretanto objeto de um prémio nacional de boa prática de atuação junto do património cultural, mereceu atenção e interesse por relacionar a salvaguarda do património e o envolvimento da comunidade, igualmente potenciando a ressocialização de pessoas em situação de liberdade condicionada.

Com uma reflexão sobre o recurso às metodologias cocriativas e colaborativas de intervenção, nomeadamente na requalificação de espaços públicos urbanos, com o ensaio "O azulejo como oportunidade cocriativa para (re)invenção do espaço público", a autora Marluci Menezes encerra o presente dossiê. A reflexão discute a cocriação como dispositivo do placemaking, olhando casos em que estas dinâmicas fizeram uso da matéria azulejar em contextos urbanos associados às realidades portuguesa e brasileira.

Os artigos aqui disponibilizados tratam de uma pequena amostra da pesquisa e reflexão sobre a multifacetada e complexa problemática da conservação e reabilitação urbana e de edifícios, considerando o seu envolvimento com as comunidades e a sua influência no social. A partir de olhares particulares, estudos de caso, análises e relatos de experiências específicas, estes artigos dão-nos a conhecer diferentes e ricas perspetivas de abordagem do tema a partir das realidades brasileira, espanhola e portuguesa.

\section{Agradecimentos}

Somos gratas à revista CIDADES, Comunidades e Territórios o apoio e interesse manifestados pelo ENCORE 2020, em especial a Maria Assunção Gato e a Mariana Leite Braga pela profissional e cuidada atenção ao longo de todo um percurso agora concretizado com este dossiê temático. Agradece-se aos avaliadores o fundamental contributo no aperfeiçoamento dos artigos, e, por fim, aos autores pelo manifesto esforço de melhoria dos textos iniciais apresentados ao evento, entretanto transformados em artigos originais e em consonância com as observações realizadas por pares de reconhecido mérito.

Marluci Menezes, Investigadora Auxiliar no Laboratório Nacional de Engenharia Civil.

Maria do Rosário Veiga, Investigadora Principal no Laboratório Nacional de Engenharia Civil.

Editoras do Dossier 